\title{
Maternal Mortality Ratio at a University Hospital in Somaliland: 17 Years Experience
}

\author{
Amal Farah ADAN ${ }^{1}$, Shukri Mohamed DAHIR ${ }^{1}$, Abdirizak Osman \\ MOHAMED $^{1}$, Edna ADAN ISMAIL ${ }^{1,2}$
}

The International Federation of Gynecology and Obstetrics (FIGO) and World Health Organization (WHO) have defined Maternal Mortality Ratio (MMR) as number of women dying from any cause while pregnant or within 42 days of its termination irrespective of its duration and site of pregnancy per 100.000 live births (1). When long-term global trends are considered for maternal mortality, it is striking that every $100^{\text {th }}$ to $200^{\text {th }}$ birth led to the mother's death (2).

\section{Maternal Mortality Ratio (MMR) Worldwide}

The leading causes of maternal mortality are classified as direct or indirect. Direct causes are those related to obstetric complications of pregnancy, labor and delivery, and the post-partum periods. Direct causes account for $80 \%$ of maternal deaths (3). Indirect causes are those relating to pre-existing medical conditions that may be aggravated by the physiologic demands of pregnancy. Worldwide, approximately 300.000 women die each year due to pregnancy related complications (4).

Hypertensive disorders complicating pregnancy are common and pre-eclampsia and eclampsia are the major causes of maternal morbidity and mortality. Globally, $10 \%$ of all pregnancies are complicated by hypertension, while pregnancyinduced hypertension cases comprise $5-8 \%$ of the whole (5).

\section{Maternal Mortality Ratio in Low-Income Countries}

The MMR in low-income countries is always higher and in 2017 averaged 462 per 100.000 live births, versus 11 per 100.000 live births in high income countries. According to the Fragile States Index, 15 countries were considered to be "very high alert" or "high alert" for MMR, including South Sudan, Somalia, Central African Republic, Yemen, Syria, Sudan, the Democratic Republic of the Congo,

\footnotetext{
1 Maternity Hospital, Edna Adan University, Hargesia, Somaliland

2 Corresponding Author

DOI: 10.17932/EJOH.2020.022/ejoh_v01i1009
} 
Chad, Afghanistan, Iraq, Haiti, Guinea, Zimbabwe, Nigeria and Ethiopia since these countries had MMR ranging from 31 in Syria to 1.150 in South Sudan in 2017 (6).

Sub-Saharan Africa and Southern Asia accounted for 254.000 (86\%) of the estimated global maternal deaths in 2017. Sub-Saharan Africa alone accounted for roughly two-thirds (196.000) of maternal deaths, while Southern Asia accounted for nearly one-fifth (58.000).

Southern Asia achieved the greatest overall reduction in MMR between 2000 and 2017, with a decline of nearly $60 \%$, from an MMR of 384 down to 157 . The statistics of sub-Saharan Africa are also encouraging according to the United Nations Inter-Agency Estimates statistics, indicating that from 1990 to 2015, the global MMR declined by $44 \%$ - from 385 deaths to 216 deaths per 100.000 live births (7).

\section{Maternal Mortality Features of Somaliland}

The first report of The World Health Organization (WHO) on MMR for Somaliland was 1.044 per 100.000 live births and belonged to the period of 1994-1996 when the state was at its youngest stage (8). The MMR has declined to 955 in 2011. The numbers are estimates only, because similar to many of the other low-income countries, the majority of maternal deaths in Somaliland occur outside the health facilities and there are no functioning civil registration systems to keep track. One fact is certain, maternal deaths are twice as high in rural areas than urban $(40.6 \%$ vs $20.7 \%$ ), and this ratio remains more or less unchanged (8).

\section{Maternal Mortality Ratio at the Edna Adan University Hospital}

The Edna Adan University Hospital (EAUH) is a not-for-profit charity since 2002. It was stablished as a Maternity Hospital but because of public demand and need, it also became a general and referral hospital for medical, surgical and pediatric patients. Since that date, 62.000 patients were treated as inpatients and 235.000 as outpatients, and 26.036 women have been assisted to deliver babies.

Among the 26.036 women who gave birth, 69 women were lost due to maternity causes, making the MMR at the EAUH to be 265 per 100.000 live births. This is far below the MMR of the country which is estimated by WHO to be 829 in 2017. In spite of the fact that the EAUH receives a high number of complicated and referred cases, the MMR of the hospital is about one third of the national average and although a great reduction has been managed, the MMR is considered as still too high. A further reuction could not be achieved due mostly to the fact 
that women were brought to the hospital too late when their conditions had deteriorated to the terminal point. Eclampsia, post-partum haemorrhage and anemia were the leading causes of MMR at EAUH. Puerperal infection, prolonged or obstructed labour, ante-partum haemorrhage, pulmonary embolism, maternal distress, cardiac failure was among other causes. Although the incidence of is on the decline due to improved diagnosis and management, pre-eclampsia and eclampsia still remain the major contributor to poor maternal and fetal outcome in developing countries (1).

A major contribution to the prevention of maternal mortality starts with the community and the quality of the antenatal care women receive during each pregnancy, as well as the training quality of the health workers and the emergency preparedness of the facility. EAUH has 1.000 midwives providing pregnant Somaliland women with medical monitoring, treatment and education.

\section{References}

1. Maternal mortality. WHO. Available at: https://www.who.int/newsroom/fact-sheets/detail/maternal-mortality

2. UNFPA. (2018). In United Nations Population Fund. Retrieved from https://www.unfpa.org/about-us

3. Lewis G. Maternal mortality in the developing world: why do mothers really die? Obstetric Medicine 2008; 1: 2-6.

4. The Millennium Development Goals Report 2015. United Nations Development Program. Available at: https://www.un.org/ millenniumgoals/2015_MDG_Report/pdf/MDG\%202015\%20rev\%20 (July\%201).pdf

5. Cummingham F. Gray et al. Williams Obstetric. $24^{\text {th }}$ edition, Chapter 24, Hypertensive disorder in pregnancy. McGraw Hill Medical Publishing Division, 2014; 706-749.

6. The Fund for Peace. Fragile States Index. Washington, D.C.: The Fund for Peace. Accessed through Resource Watch. https://reliefweb.int/ report/world/fragile-states-index-2017

7. Trends in Maternal mortality 2000 to 2017. World Health Organization, UNICEF, World Bank Group, the United Nations Population Division. Available at:

8. https://apps.who.int/iris/bitstream/handle/10665/327596/WHO-RHR- 
19.23-eng.pdf?sequence=13\&isAllowed $=y$

9. Maternal Mortality in Somalia: What ARC is doing to combat this crisis. Available at:https://reliefweb.int/report/somalia/maternal-mortalitysomalia-what-arc-doing-combat-crisis\#: :text=Women $\% 20 \mathrm{in} \% 20$ Somalia \%20have\%20a,deaths\%20per\%20100\%2C000\%20live\%20 births. 